\title{
Comparison of Three Models Dealing with Working Memory and Its Dimensions in Second Language Acquisition
}

\author{
Abdulaziz Alshahrani* \\ Department of Foreign Languages, College of Arts and Humanities, Albaha University, Albaha City, Kingdom of Saudi Arabia
}

Corresponding Author: Abdulaziz Alshahrani, E-mail: a.shahrani@bu.edu.sa

\section{ARTICLE INFO}

\section{Article history}

Received: August 06, 2017

Accepted: October 09, 2017

Published: January 05, 2018

Volume: 7 Issue: 1

Advance access: December 2017

\section{Conflicts of interest: None}

Funding: None

\begin{abstract}
The current status of research on working memory (WM) and its components in second language acquisition (SLA) was examined in this review. Literature search was done on four aspects using search terms in Google Scholar. Hence, the review results are given and introduced. 1. In the definition of WM, some confusion exists on whether short term memory (STM) or recent memory is the same as WM or different. 2. In this review, three main models have been discussed elaborately, as they are the only ones discussed in literature. They are: multicomponent model of Baddeley (2000), embedded process model of Cowan (2005) and attention control model of Engle and Kane (2003). 3. The phonological and executive components of WM were examined in more detail, as these determine the two basic aspects of language acquisition: language characteristics and acquisition methods (Wen, 2012). Overall, the variables related to phonological and executive working memories are evident from published research, but their interactive relationships and affecting factors are not entirely clear. 4. Admittedly, several diverse internal and external factors affect WM in relation to SLA. Some practically useful interventions are indicated by certain findings
\end{abstract}

Key words: Working Memory, L2 Acquisition, Phonological Memory, Short Term Memory

\section{INTRODUCTION}

The way people process and store linguistic information related to a language and its learning is partly responsible for their learning performance in second and foreign languages. The method of storage is committing what was learned first into an immediate memory, called working memory (WM). It is a part of the short-term memory (STM). It is a high speed memory used for storing currently used information and data. WM has limited storage capacity and is a temporary function (Baddeley \& Hitch, 1974).

Working memory is, sometimes, used as a synonym of STM. But some theorists consider the two as distinctly different (Atkinson \& Shiffrin, 1968). In WM, manipulation of stored information is possible. On the other hand, STM is only the short-term storage of information.

WM is a term that is related to the cognitive psychology of language processing. There are many barriers including the ability of the learner to access to information while learning a second language. WM can be considered as a significant moderator of SLA as is pointed out by (Churchill \& Elton, 2002).

Many models of WM have been suggested, of which three are important as they are widely researched. Definitio al issues of WM also get into these models. Much research work has been one on two specific aspects of WM- phonological and executive memory. Both aspects have important applications in the WM related to Second Language Acquisition (SLA). WM is affected by many factors. Knowledge of these factors is highly essential when working memory is manipulated for SLA. There had been very limited reviews to take stock of research work done on WM and its applications in SLA.

In this qualitative review, after considering issues related to definitions, three models of WM are compared. Special attention is given to phonological memory and executive memory as certain issues of WM are specific to them. Various factors affecting WM are discussed in the subsequent section. The conclusions are introduced on the basis of these points.

\section{METHODS}

Being a review work, this research is secondary in nature. Information published in various research works have been collected, collated and discussed under different topics. The approach is qualitative as the information contained in the reviewed works are only discussed and interpreted. The number of researches accessible with the search strategy limits the scope of the work.

In this paper, four aspects of WM in L2 acquisition are examined using published works. First, the impact of different definitions of WM on methodological aspects is 
reviewed. The research approaches depend on whether the STM is considered synonymous to WM or not. Fluid memory is a better test than STM. Second, the proposed models of WM and their evaluation by the relevant supported research are discussed. Primarily, there are three models. A few derivatives of these models and some theoretical frameworks are reviewed here. Third, phonological memory, as a part of WM, is a separate side of research and deserves a special section. Two components- executive working memory and phonological working memory- have been suggested in the framework proposed by Wen (2012). Phonological working memory seems to be more relevant in L2 acquisition as revealed by the reviewed works. The issue of phonological memory arises when retrieval of phonological characteristics of a language from WM is considered. Therefore, a lot of the available works on this aspect are reviewed here. Fourthly and finall, various factors of WM, investigated by many authors have been reviewed to demonstrate the large variety of factors involved in WM in the context of L2 acquisition. One significant factor is the differentiation of a working memory capacity in central executive component of the attention control model of Engle and Kane (2003). Many works are available on this aspect. Hence, working memory capacity has also been given a detailed treatment.

Google Scholar was used as the main search engine to find published works on various topics. The search yielded 48 papers in total.

\section{RESULTS}

\section{Definitions of Working Memory}

As is evident from the conceptual differences, there are many definitions of WM. The most accepted definitions, with their sources in parenthesis, are given below.

Working memory is a system for temporarily storing and managing the information required to carry out complex cognitive tasks such as learning, reasoning, and comprehension. Working memory is involved in the selection, initiation, and termination of information-processing functions such as encoding, storing, and retrieving data (Medicine Net, 2017). In this definition, STM and recent memory are considered synonymous to WM. However, measures of WM have been associated with intellectual aptitudes, especially fluid intelligence, to a greater extent than the measures of STM.

The differences between short term, long term and working memory with definitions were discussed by Cowan (2008). According to Cowan (2008), STM reflects faculties of the human mind that can temporarily hold a limited amount of information in a very accessible state. STM differs from primary memory in that primary memory might be more restricted. WM is not completely distinct from STM. The term WM was first used by Miller et al. (1960 - as cited by Cowan, 2008), to mean memory as it is used to plan and carry out behaviour. The difference between short and long-term memories lies both in their duration and in their capacity.

\section{Brief History of WM}

WM became popular in learning research when Baddeley and Hitch (1974) used it to propose an influential model. In this model, there was a separation of verbal-phonological and visual-spatial representations. These were managed and manipulated through attention-related processes, which was named the central executive. In their first version (Figure 1), this central executive could have its own memory crossing all domains of representation.

A fourth component, episodic buffer, was added to this model in the later version of 2000 (Baddeley, 2000). The central storage and processing component was required to explain short-term memory of features that did not match the other stores (particularly, semantic information in memory) and to explain cross-domain associations in working memory like remembering names and faces together. The revised model is presented in Figure 2.

The model of Baddeley led to the acceptance of multiple components for the memory and recall systems of language learning. In some multicomponent models, larger role is assigned to an added component of long term memory to reduce the load of short term memory. In some usual research methods, concurrent engagement of both storage and processing is required to assess working memory capacity, so that it can be related to cognitive aptitude. Engle, Tuholski, Laughlin, and Conway (1999) noted that both aptitudes and working memory depend on attentional control, or they might apply attentional control to manage both primary and secondary memories.

The construct of WM has a decades-long history within cognitive psychology and a large number of empirical

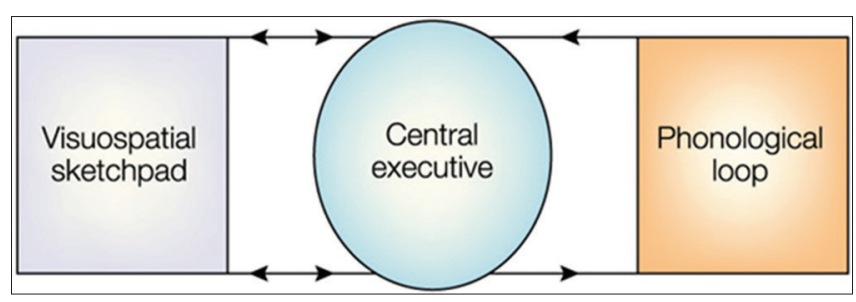

Figure 1. The working memory model proposed by Baddeley and Hitch (1974)

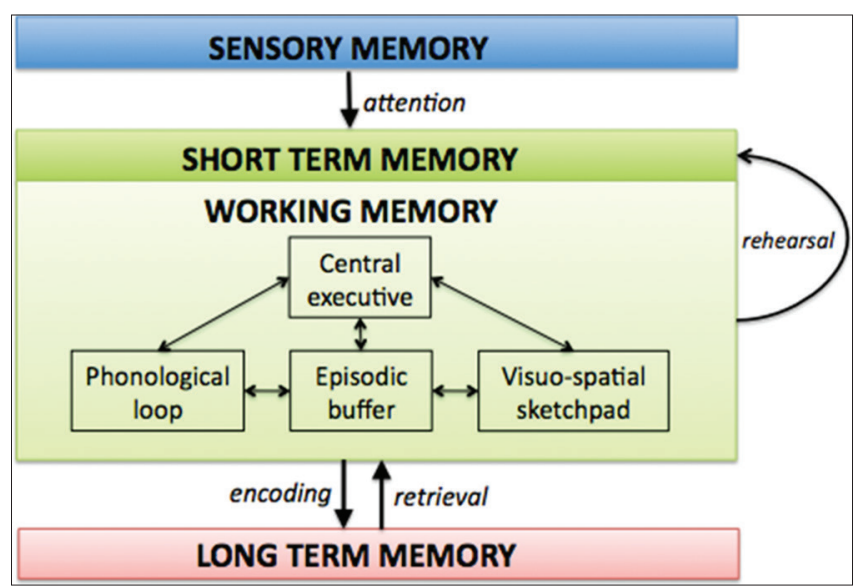

Figure 2. Revised model of (Baddeley, 2000) incorporating episodic buffer as the fourth component 
studies support its influence on the second language acquisition (SLA). Several theoretical accounts, varying in detail, have been posited to explain WM. These accounts lend insight into the results obtained by second language (L2) researchers.

\section{Association of Different Memories with Second Language Acquisition}

In one of the early works on memory, Robinson (1995) evaluated noticing hypothesis of Schmidt (1990) in relation to attention, awareness, and detection. Schmidt (1990), in his noticing hypothesis, claimed that consciousness, as a form of awareness in the form of input to the level of noticing, is required for SLA. Out of the three functions of alertness, detection and orientation, detection is the closest to noticing. Robinson (1995) defined noticing to mean detection with rehearsal in short term memory before encoding into long term memory. These relationships are explained in Figure 3 reproduced from Robinson's work.

In the above scheme, activation in STM should exceed a certain threshold level before it is converted to awareness. Therefore, noticing can be identified by what is detected and further activated after attentional resources are allocated to it. This definiti $\mathrm{n}$ was required for encoding what has been learned into a long-term memory. Interaction of attentional resources with task demands dimensions are two aspects to attend. Individual differences and attentional resources reflect in extent of noticing and consequent L2 development

Audio-lingual approaches to SLA placed a high emphasis on memorisation for learning. Both short-term and longterm memories have been associated with SLA. Short-term and long-term memories are also associated with conscious and unconscious retrieval of information for use. In the case of the long-term memory, explicit memory is more useful in SLA as it helps to recall words more quickly. On the other hand, implicit memory, although lasts longer, is not directly involved in recalling materials. The two types of memories have differential usages in remembering and using words, phrases, and sentences. Short-term and long-term memories have been differentiated functionally. STM has sometimes been regarded as a subset of the long-term memory in a currently activated state. STM is an interface of what is known and what is seen or done. Performance in STM tests were more similar among adults in the case of L1. More complex learning tasks may be associated with the long-term memory.

In a subsequent review, Robinson (2005) discussed research works and their methodologies on the cognitive abilities associated with implicit, incidental, and explicit learning and in learning and performance of tasks differing in their information processing demands. A new theoretical framework was proposed to explain aptitude and development of L2 in different learning contexts. The framework is reproduced in Figure 4.

The key to Figure 4 is given in Figure 5 reproduced from the same article. As per this code, in Figure 4, ten basic cognitive principles have been given in the innermost circle, abilities. Out of these, six - Phonological Working Memory Capacity (PWMC), Phonological Working Memory Speed

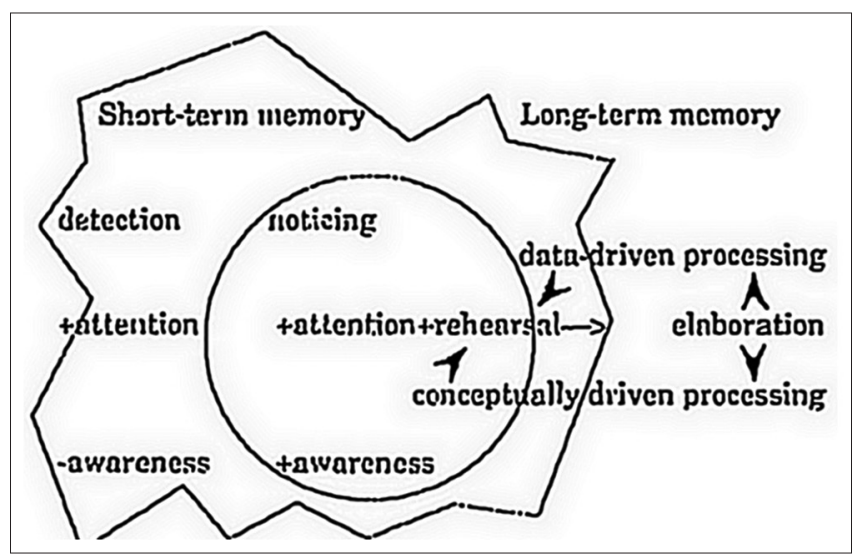

Figure 3. Noticing as detection with awareness in short-term memory and position of long term memory in second language acquisition (Robinson, 1995)

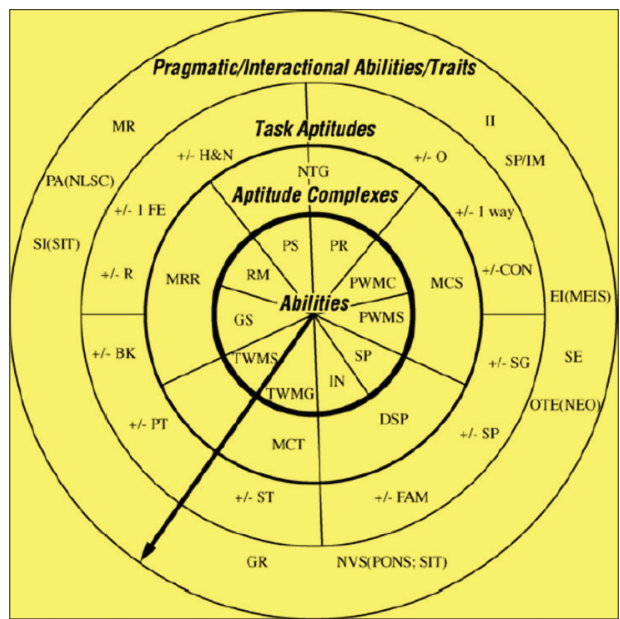

Figure 4. Aptitudes, development, and learning contexts: Changes in the relative contribution of aptitude factors to different aspects of L2 learning (Robinson, 2005)

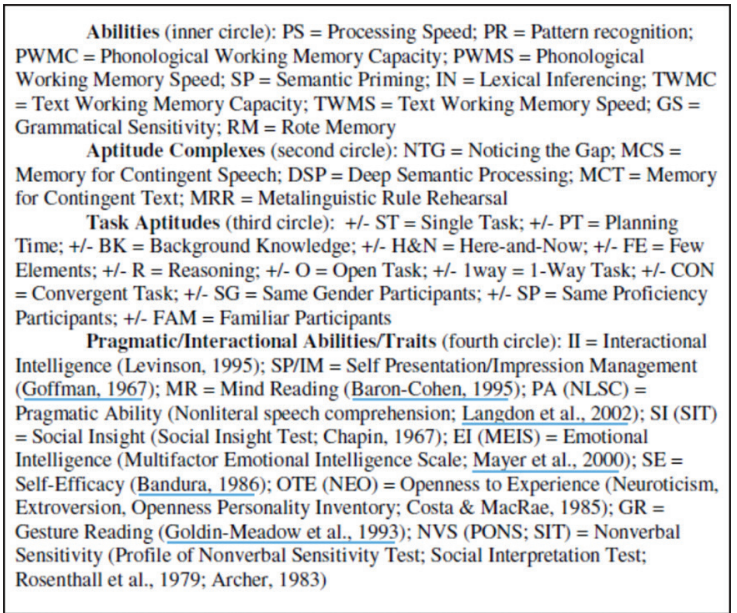

Figure 5. Key to Figure 3 (Robinson, 2005)

(PWMS), Text Working Memory Capacity (TWMC), Text Working Memory Speed (TWMS), and Memory (RM) are abilities related to different types of memories. In the second circle, out of five aptitude complexes, two - Memory for Contingent Speech (MCS) and Memory for Contingent 
Text (MCT) are different types of memory related aptitudes. Thus, there are different memories associated with different abilities and tasks.

\section{Models of WM}

Three basic types of models have been used by researchers: multi-component model of Baddeley (2012), embedded process model of Cowan (2005) and attention control model of Engle and Kane (2003). These are given in Figure 6. The differences between them has been tabulated and discussed by Fenesi, Sana, Kim, and Shore (2015). Multicomponent and embedded process models have some hierarchical structures. Attention control model is not structured hierarchically. Limited storage of WM is assumed in the multicomponent model. In the attention control model, capacity for

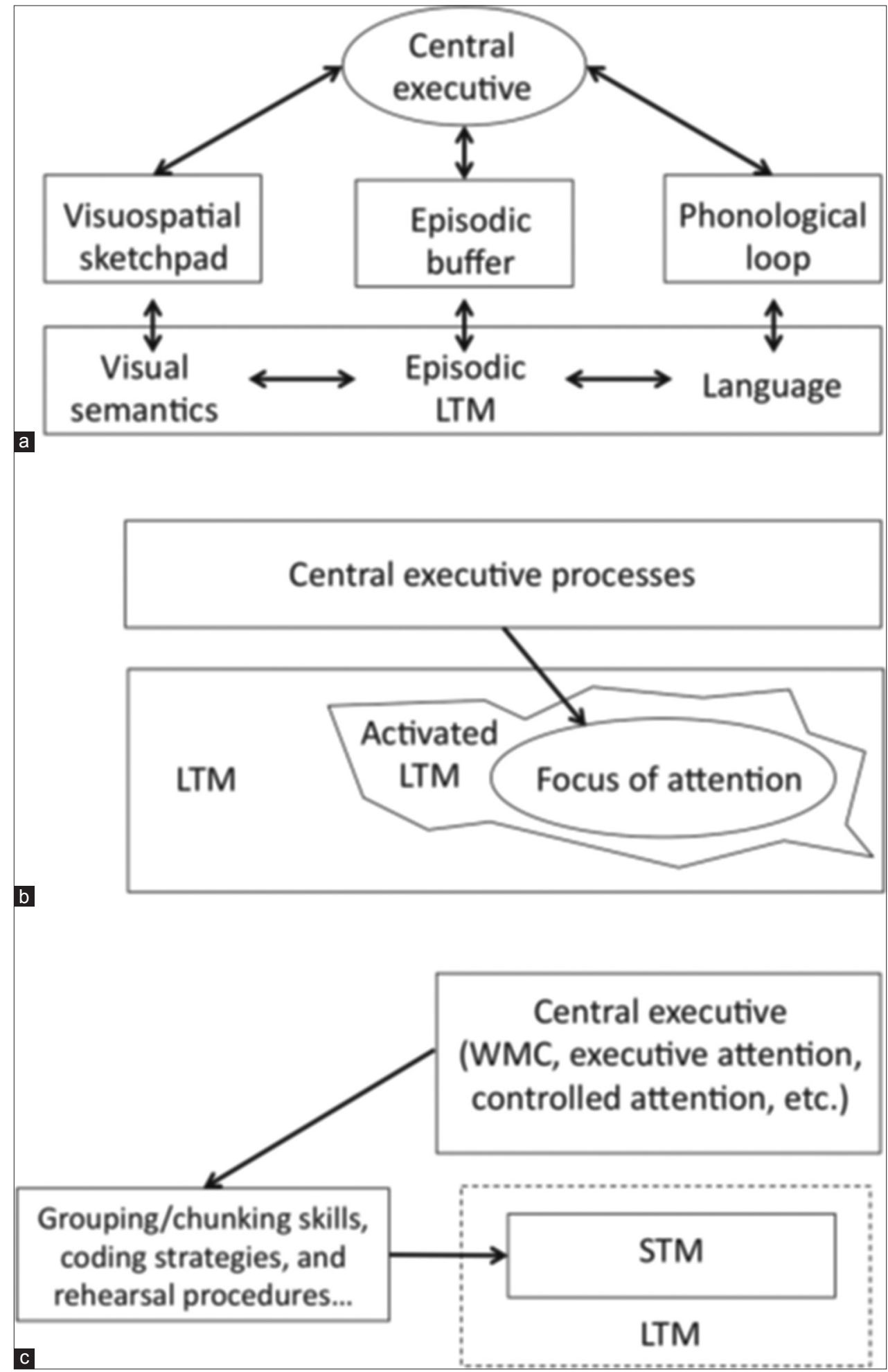

Figure 6. The multi-component model of Baddeley (2012), embedded process model of Cowan (2005) and attention control model of Engel and Kane (2003) from Jackson (2016) 
controlled and sustained attention is assumed, but no such assumption is made for storage in this model. The embedded process model assumes limited, but flexible capacity. Central executive coordinates resource allocation and hence is the general domain in the multicomponent model. The attention control model emphasises on attention control as the central command. Focused attention is assumed to drive WM in the embedded process model. Domain-specific stores have been assumed in all models, but they differ in detail. Integration of the long-term memory is assumed in attention control and embedded process control models, but not in the multicomponent model. Clearly, these differences are reflected in the research methodology and in the identified effects found in the $\mathrm{L} 2$ research works.

Using reading span test as a measure of working memory capacity, Harrington and Sawyer (1992) evaluated the L2 reading skills of advanced L2 learners. Larger working memory capacity was associated with higher reading skills. Passive short-term storage of words or random word strings was not correlated with the reading skills. Here, capacity was functionally the trade-off between active processing and storage. Capacity limitations of L2 learning is an important issue. Thus, the assumption of limited capacity in the three models is verified. Resource allocation controlled by central executive might be responsible for managing the capacity limitation via the trade-off reported in this work. Thus, there is more support for the multicomponent model from this result.

Izumi and Bigelow (2000) aimed at examining whether the target language activity output affected noticing. Improvement in learners' use of the grammatical structure was found to be facilitated by extended opportunities to produce output and receive relevant input. However, that output could not always attract the attention of the learners to the target form, which may be related to both learner and linguistic factors. Thus, attention control model is contradicted in this case.

Juffs (2004) showed that the basic mechanisms of grammar remain intact for the L2 learners despite inferior performance with respect to judgement of the same sentences used in the grammar test. Data suggested that WM did not account for individual variation in the online L2 performance consisting of online processing of English. The sample was constituted of thirty Chinese-speaking, twenty-eight Japanese-speaking and forty-six Spanish-speaking participants. However, the words span could be affected by working memory. This work demonstrated general defect of all the above three models, shown by their inadequacy of explaining individual differences.

According to Skehan and Willis (1996), the difficulty of tasks could be analysed using the two general categories of language factors and cognitive factors. In cognitive factors, the question arises whether the task simply requires the learners to produce a well-organized language from memory in a ready-organized chunk or a new or less-organized material to be drawn from memory. The chunk theory is a characteristic of embedded process model.

Thus, there is some support from a number of published works to the above models in varying degrees. There is a greater support for the multicomponent model as this model has the longest history and has been tested and/or used by more researchers than the other two models.

\section{Working Memory: Phonological Memory and Executive Working Memory}

In a review article, Wen (2012) proposed an integrated framework of WM and SLA based on some principles. Part of this framework was used in an empirical study. The roles of phonological working memory (PWM) and executive working memory (EWM) reported by different authors was summarised by Wen. An adapted version of this summary is reproduced in Table 1.

The principles suggested by Wen for the integrated framework areas are: Principle 1- the constituent components of WM should be treated separately in WM/SLA studies as they are purported to exert distinctive influence on different aspects of SLA; Principle 2 - a domain-specific view (rather

Table 1. Summarisation of reported findings on the roles of phonological and executive working memories adapted from (Wen, 2012)

\begin{tabular}{lll}
\hline Activities & PWM & EWM \\
\hline $\begin{array}{l}\text { Vocabulary } \\
\begin{array}{l}\text { Acquisition } \\
\text { Acquisition }\end{array}\end{array}$ & $\begin{array}{l}\text { Long-term learning of phonological forms of new words } \\
\text { depends heavily on this }\end{array}$ & $\begin{array}{l}\text { Interpretation of the semantic characteristics of new } \\
\text { words is made possible by this }\end{array}$ \\
$\begin{array}{l}\text { Language } \\
\text { comprehension }\end{array}$ & $\begin{array}{l}\text { This is useful in maintaining a phonological record for } \\
\text { consultation for off-line language processing }\end{array}$ & $\begin{array}{l}\text { Processing of syntactic and semantic information } \\
\text { and storing products of processing are done using } \\
\text { this }\end{array}$ \\
$\begin{array}{l}\text { Language } \\
\text { processing }\end{array}$ & No clear trend so far & This is required for noticing feedback \\
$\begin{array}{l}\text { Written } \\
\text { Production }\end{array}$ & $\begin{array}{l}\text { This is useful for translation of ideas and reading } \\
\text { process }\end{array}$ & $\begin{array}{l}\text { Planning, translating, programming, reading and } \\
\text { editing require this }\end{array}$ \\
Production & $\begin{array}{l}\text { Promotes Narrative ability is promoted at early stage } \\
\text { and accuracy promoted at later stage. But this theory is } \\
\text { not conclusive }\end{array}$ & No clear trend so far \\
\hline
\end{tabular}


than a domain-general view) needs to be adopted for constructing complex memory span tasks to measure the EWM in WM/SLA studies targeting specific L2 activities or the four basic subskills for L2; Principle 3 - WM should not be treated as a dichotomous variable but as a continuous variable. Then, a total performance score, not a maximum set size score, will be more suitable for scoring procedure in WM span tasks; and Principle 4 - in WM/SLA studies, more possible effects of WM should be considered in studies using many different research designs to evaluate their respective effects (See Figure 7).

The proposed integrated framework of PWM and EWM for speech performance is reproduced in Figure 8. The framework has three parts: aspects of L2 speech, measures which will serve as index of L2 speech and which of the two WM (PWM or EWM) is applicable. Fluency, accuracy, and complexity are three factors, which affect the speech acquisition. Measurements for indexing each of these aspects are listed. Implications of the aspects and their measurement indexes have distinct non-interacting relationships with PWM and EWM. Generally, structured tasks have no direct effect from PWM or EWM.

In incidental adult learning, phonological working memory was not related to the learning outcomes in the results obtained by Grey, Williams, and Rebuschat (2015). Using hierarchical regression analysis, Swanson, Orosco, Lussier, Gerber, and Guzman-Orth (2011) showed that, not only phonological processing, naming speed and inattention, WM and STM also accounted for significant variance to L2 reading and language acquisition. No significant cross-language effects were shown by regression modelling when L1

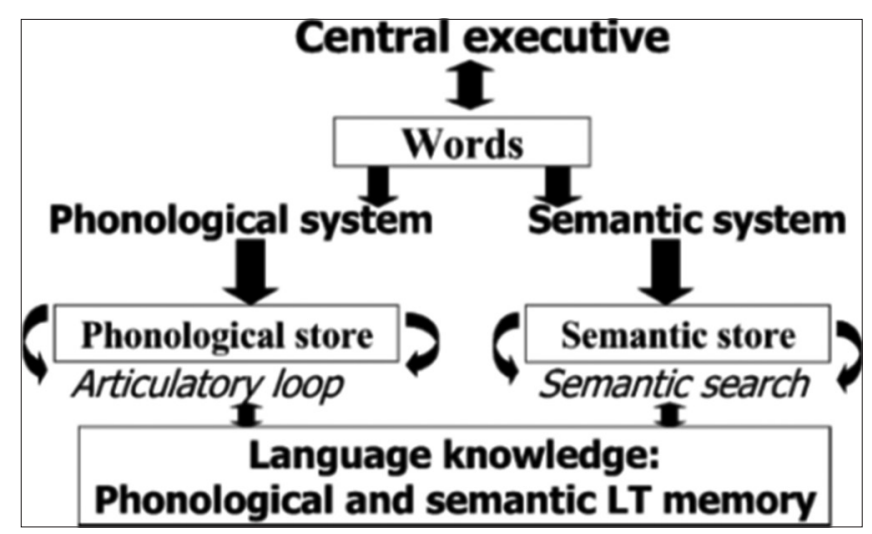

Figure 7. WM model for L2 acquisition (Ardila, 2003) measures were included into the analysis. Both STM and WM contributed to the individual variances to $\mathrm{L} 2$ reading and language acquisition more than the contribution of L1 phonological processing skills. As was discussed in the definitions section, sometimes, WM and STM are treated separately. This work is one example of such differentiations.

The aim of the research reported by Hummel and French (2016) was to evaluate the relationship between phonological short-term memory (phonological memory, PM), language learning aptitude and second language (L2) proficiency in advanced adult L2 learners, who had largely homogeneous previous and current L2 experience. The results revealed continuing association between phonological memory, aptitude and L2 proficiency in the advanced learners

Vulchanova, Foyn, Nilsen, and Sigmundsson, (2014) reported that the overall language competence was related to short-term memory supporting earlier findings. Correlations between STM, L1 competence and L2 skills were obtained. Thus, memory may be a common mechanism for any language learning. L1 competencies in lexical knowledge was correlated with competencies in grammar. There was correlation between vocabulary size and sentence comprehension in the case of SLA. STM was correlated more with syntax than with morphology. Phonological loop seemed to mediate mediated syntactical learning, but not morphological learning. These results were supportive to Baddeley's model.

In a study, Martin and Ellis (2012) evaluated the relationship of the phonological short-term memory (PSTM) and working memory (WM) with vocabulary and grammar learning at an artificial foreign language. Significant independent effects of PSTM and WM on L2 vocabulary learning and on L2 grammar learning were noted. Some of these effects were mediated by vocabulary and some effects were due to direct effects. However, correlation coefficients ranging 0.44 to 0.76 were obtained for individual differences in final abilities of vocabulary and grammar as affected by various measures.

From the results of their work, Kormos and Sáfár (2008) identified some different roles of the phonological short-term memory capacity in the case of beginners and pre-intermediate students in intensive language learning. The backward digit span test, used in this work, correlated very highly with the overall English language competence with respect to reading, speaking, and listening and using of English measured by vocabulary and grammar test scores.

The variables related to phonological and executive working memories are evident from the above discussions

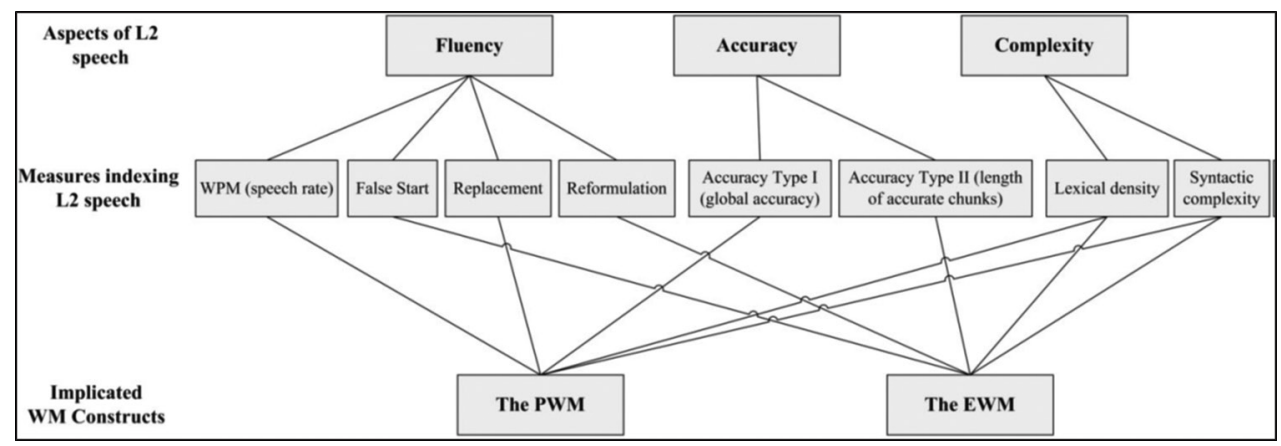

Figure 8. The proposed integrated framework of PWM and EWM in L2 learning (Wen, 2012) 
of various works in different research contexts. Although a clear distinction between the two types of WM is possible, their interactive regimes and affecting factors are blurred.

\section{Factors Affecting WM and its Components}

In a review, Juffs and Harrington (2011) pointed out that the role of WM was not a single entity, but varies depending on the linguistic domain, the nature of the task and the age of the L2 learners. Some tests of WM might be able to differentiate abilities of attending to different aspects of the L2. In the research contexts, where self-paced reading with high-load ambiguity in syntactic processing has been tested, there was weak robustness in detection of effects of individual differences on memory spans. When the effects were detectable, mediation by factors like prior knowledge or pragmatic inferences was noticeable. In the very few available interaction-based studies, listening span tests may predict the output which needs to be confirmed by further research. Both Reading Span test and Listening Span test have been most successful in explaining some variation in hitherto published research. However, how this test method correlates with a wide variety of domains, such as lexical, gender agreement and syntactic processing, in L2 learning is unclear. Perhaps, PM tests are very robust predictors of early language development. But only limited effects of PM on subsequent lexical development has been observed and thus cannot predict the gains after the establishment of basic vocabulary. WM may be a form of attentional control for later learning. Differences in success in language learning may be due to this ability to control attentional resources and suppress competing information sources rather than memory. This may be what is being measure by WM tests. In the instructional context, emphasis on oral-aural learning in communicative language classrooms, might adversely affect low WM learners, like those with learning disabilities. In such cases, additional multi-modal support with multimedia learning tools such as online dictionaries and electronic glosses might help. For example, online synchronous chat enables low WM learners to produce the same quantity and complexity of output as higher WM learners. This effect is due to the reduced cognitive burden and increased planning time that these tools provide. Increased exposure and use of visual aids facilitate the development of communicative activities, including writing skills, by reducing cognitive load and compensating for lower WM capacity. For text-based processing to increase reading ability, limited extent of reading aloud might work as rehearsals and thus promote the phonological loop component of WM. If WM is an unchangeable trait, it cannot be altered to improve language learning. If, on the other hand, WM is linked to attentional capacity or control of the central executive function, it can suppress the competing pressure from the L1. In that case, learners could be assisted in focusing on L2 forms and attempting to suppress L1 influence. In any case, L1 transfer seems to be inevitable. Learning to control attentional resources may lead to more successful L2 learning.

Most adult learners cannot attain native competence in a second language (L2). In a study aimed to investigate the role of language proficiency and WM on adult L2 acquisi- tion by Sagarra and Herschensohn (2010), beginning and intermediate adult English-speaking learners of Spanish and Spanish monolinguals completed a self-paced reading (online) and a grammaticality judgment task (offline) noted that high accuracy was shown in the offline tasks by all participants. However, gender sensitivity and increased violations in online tasks were observed only in the case of intermediate adult English-speaking learners of Spanish and Spanish monolinguals. Intermediate adult English-speaking learners of Spanish with higher WM were also more accurate on some comprehension questions. Thus, the effect of WM in language acquisition was mediated by proficienc . Here, there were no individual differences. But gender differences were detected.

Working Memory Capacity (WMC) is an integral part of central executive in the attention control model of Engle \& Kane (2003). Some works specifically dealt with this factor. With the aim of finding out how WMC is related to the extent to which learners can benefit from recasts and metalinguistic feedback among EFL learners, reading span and operation span tests were conducted by Goo (2012). In the results, recasts were as effective as metalinguistic feedback in facilitating the acquisition of the target construction. Blocking of modified output opportunities specifically designed in this study could have caused this effect. Executive attention or attention controls, which are critical components of WMC, might have been involved in the noticing of recasts, but not metalinguistic feedback. Thus, the attention control model was supported by this work.

The hypothesis that WMC interacts with (foreign) language proficiency was verified in the study by Van den Noort, Bosch, and Hugdahl (2006) on multilinguals as differences in performance between L1, L2, and L3 were observed on both simple and complex working memory tasks. This finding provides direct evidence in favour of the embedded process model.

In a research on interaction and WM, Mackey and Sachs (2012) only observed the L2 development in the older (6589) learners with the highest scores on a first-language listening-span test of WM. Just as gender differences identified in a research above, age differences were observed here. As age increases, the WMC may be reduced, requiring greater effort from the learner. In this condition, only the highest performance in L1 facilitates the L2 development. There may be a trade off in the capacity from L1 and L2. But this is a pure conjecture.

In a study on Spanish as L2 language acquisition, Leeser (2007) examined how topic familiarity and WMC affected the Spanish learners' reading comprehension and their processing of future tense morphology in their learning early stages. There were consistent effects for topic familiarity on all tasks. Differences in WMC played some roles in the learners' comprehension and processing grammatical forms. However, the effects of WM depended mainly on the participants' familiarity to a topic. Of the many factors determining WM, including those discussed above, familiarity of the topic is somewhat a decisive one.

In his work, Tellier (2008) studied the effect of gestures 
on L2 memorisation by very young learners. Learning words with gestures and reproduction in the same manner improved the memorisation of L2 lexical items significantl . This result was noticeable especially in the case of active knowledge of the vocabulary. The improved effect on active knowledge was reflected in the ability to produce words apart from understanding them. These findings supported theories on multimodal storage in memory. Reproduced gestures acted both as a visual modality as well as a motor modality, leaving a richer trace in memory.

A study on late adults by Erçetin and Alptekin (2013) explored the relationships between L2 language explicit/implicit knowledge sources, embedded in the declarative/procedural memory systems and WMC of L2. The relationships between L2 reading comprehension and L2 WMC were also examined. In addition, how L2 reading comprehension and L2 explicit/implicit knowledge sources were related, was another subject of the study. Significant relationships were obtained between L2 WMC and both explicit and implicit L2 knowledge. According to exploratory factor analysis, explicit knowledge, WMC and L2 reading comprehension were loaded on a single factor. On the other hand, implicit L2 knowledge was an independent factor without the relationship to the $\mathrm{L} 2$ reading. L2 WM, through controlled and automatic processes, could manipulate and store both explicit and implicit L2 input. L2 explicit knowledge was linked with the control processes of the declarative system's lexical/semantic features. L2 WM of the second language reflected attentional resource capacity/allocation associated with the control processes and it played an important role in the $\mathrm{L} 2$ reading comprehension. Here, a separate L2 WM has been recognised. However, there was no description or discussion of the L1 WM or how the two WMs act or interact.

A study was undertaken by Alptekin and Erçetin (2015) to examine whether eye movement (EM) patterns reflect WM functions in the L2 among late L2 learners. The relationship between WMC using EM as an index and L2 reading comprehension was also studied. The final aim was to explore whether offline and online data could be used as predictors of the L2 reading. In the findings, the storage performance was negatively associated with fixation durations within the critical region of each sentence. This indicated a trade-off between processing and storage.

In a study on the influence of outcomes measured on the effectiveness of recasts (Révész, 2012), the greatest gains of recasts were noted on the oral production test. Lesser gains were noted on the written production test. The least one was found in the written grammaticality judgment test. In the recast group, greater development on the written tests were achieved by participants with higher reading spans. Greater improvement on the oral test was shown by those with higher digit and non-word spans. In the case of the non-recast group, there was no relationship between the working memory and developmental measures. Thus, recast is another factor interacting with WM.

From the findings of their research, Mackey, Adams, Stafford, and Winke (2010) obtained an association between the WM of learners and their tendency to modify output. Particularly, a greater production of modified output due to greater processing capacity was noted during the interaction. An intervention method for L2 acquisition is indicated by the possibility of output modification demonstrated by this work.

From a meta-analytical review, Linck, Osthus, Koeth, and Bunting (2014) concluded that WM is positively associated with both L2 processing and proficiency outcomes. The estimated population effect size was 0.255 . Larger effect sizes were observed in the executive control against the storage component of WM and for the verbal against nonverbal measures of WM. There was no publication bias indicating robust, positive relationship of WM with L2 outcomes.

Under incidental learning conditions, differential involvement of WM was noted in production of acquired knowledge. But this was not engaged when learning was facilitated by frequency in the studies by Denhovska, Serratrice, and Payne (2016). Sri Lankan English learners were tested for the role of WM in L2 processing in a study by Indrarathne and Kormos (2017). Attention paid to a target syntactic construction causative was associated with the storage capacity and attention regulation function of WM. These abilities of WM moderated the change of knowledge of the target construction in different input conditions. The gains in the knowledge of the target construction were strongly correlated with the WM abilities. There was also a strong relationship between the WM scores with gains in receptive knowledge in all input conditions. On the other hand, their association with the improvement of productive knowledge in the implicit learning conditions was weak. WM abilities were also strongly related with the amount of attention given to the input.

In his article, Wen (2014) noted that WM generally refers to the ability of temporarily maintaining and manipulating a limited amount of information in immediate consciousness, as one performs complex cognitive tasks like language comprehension. However, there is much controversy around the introduced concept due to its introduction. The multi-component model consisting of both domain-specific storage mechanisms and domain-general executive functions has been generally accepted.

Relationships between WM as measured by reading span tasks (RST) and L2 reading as affected by differences in secondary task design (semantic vs. morphosyntactic) and whether it was a task of L1 or L2 were the aims of the study by Alptekin, Erçetin, and Özemir (2014). Storage function was independent of task and language, whether L1 or L2. Processing by L 2 learners was affected by the linguistic nature of the task and the language in which it was presented. There was a significant relationship between $\mathrm{L} 2$ reading and the storage capacity of learners. Resources of L1 and L2 semantic and L2 morphosyntactic processes contributed to the L2 reading, but not in the case of those underlying L1 morphosyntactic processes.

According to the declarative/procedural (DP) model, learning, storage and use of language critically depended on two learning and memory systems in the brain: declarative memory and procedural memory. In the article by Ullman and Lovelett, (2016), an overview of learning and memory enhancement techniques have been explored with 
subsequent focus on two enhancement techniques (spaced repetition and retrieval practice) as have been linked to the memory systems. Specific predictions of the mechanisms by which these two techniques enhance language learning were provided. A review of existing evidence suggested improved learning of both first and second language by these enhancement techniques and thus validated the model. These enhancement techniques could be useful in designing L2 programmes for more effective learning on the practical side.

Verbal short-term memory (VSTM) is related to vocabulary learning, and verbal working memory (VWM) is related to grammar learning in L2 children in the classroom. In the study by Verhagen and Leseman (2016), both memory factors were significantly associated with the acquisition of morphology and syntax in the case of five-year old children. VSTM and VWM were associated with language learning differentially. The memory mechanisms employed for learning vocabulary and grammar in L1 children and in L2 children who learn their L2 naturalistically were the same.

In the research by Sagarra (2017) the aim was to evaluate the effects, if any, of WM on L2 grammar and reading developments among the beginners. The findings revealed longitudinal WM effects on L2 grammar and reading development at early acquisition stages and supported the resource-sharing WM models.

Clearly, several diverse internal and external factors affect how WM functions with respect to L2 acquisition. Some practically useful points and intervention methods have been indicated in some works. If these are pursued further, clear methods of interventions for more effective use of WM in L2 acquisition may emerge.

\section{CONCLUSIONS}

Although much work has been done on working memory and associated factors in L2 development, there is no clarity on methodological issues and explanation of individual differences. Various models have revealed the complexity of WM. Several factors associated with WM in L2 development have been explored. WM interacts with differences in L2 learning contexts and L2 learners in complex ways.

On more practical side, an aptitude complex approach (Robinson, 2005) can explore facilitation of SLA under specific conditions of WM and other cognitive abilities like analogical reasoning. Such an approach could lead to a deeper understanding of L2 learning mechanisms. In a close relationship to this, aptitude-treatment interaction research assumes that instruction can be designed to match the learner's WM abilities. More psycho-linguistically validated approaches to language teaching could be designed using such methods. An emerging line of research is the usefulness of intervention programmes like WM training of learners in order to improve their L2 language processing and acquisition. Some memory enhancement techniques like those tested by Ullman and Lovelett (2016) can improve both L1 and L2 learning and become practically useful in future.

\section{REFERENCES}

Abu-Rabia, S., \& Siegel, L. S. (2002). Reading, syntactic, orthographic, and working memory skills of bilingual Arabic-English speaking Canadian children. Journal of psycholinguistic research, 31(6), 661-678. doi:10.1023/A:1021221206119.

Alptekin, C., \& Erçetin, G. (2015). Eye movements in reading span tasks to working memory functions and second language reading. Eurasian Journal of Applied Linguistics, 1(2), 35-56. Retrieved April 24, 2017, from http:// ejal.eu/index.php/ejal/article/view/52.

Alptekin, C., Erçetin, G., \& Özemir, O. (2014). Effects of variations in reading span task design on the relationship between working memory capacity and second language reading. The Modern Language Journal, 98(2), 536-552. doi:10.1111/modl.12089.

Ardila, A. (2003). Language representation and working memory with bilinguals. Journal of communication disorders, 36(3), 233-240. doi:10.1016/S00219924(03)00022-4.

Atkinson, R. C., \& Shiffrin, R. M. (1968). Human memory: A proposed system and its control processes. Psychology of learning and motivation, 2, 89-195. doi:10.1016/ S0079-7421(08)60422-3.

Baddeley, A. (2000). The episodic buffer: a new component of working memory? Trends in cognitive sciences, 4(11), 417-423. doi:10.1016/S1364-6613(00)01538-2.

Baddeley, A. (2012). Working memory: theories, models, and controversies. Annual review of psychology, 63, 1-29. doi:10.1146/annurev-psych-120710-100422.

Baddeley, A. D., \& Hitch, G. (1974). Working memory. Psychology of learning and motivation, 8, 47-89. doi:10.1016/S0079-7421(08)60452-1.

Churchill, E., \& Elton, F. (2002). The role of working memory in SLA. Retrieved August 30, 2017, from Temple University, Japan: https://www.tuj.ac.jp/tesol/publications/ working-papers/vol-14/churchill.html.

Cowan, N. (2005). Working memory capacity limits in a theoretical context. In Human learning and memory: Advances in theory and application. In C. Izawa, \& N. Ohta (Eds.), Human learning and memory: Advances in theory and application. The $4^{\text {th }}$ Tsukuba international conference on memory (pp. 155-175). Psychology Press. Retrieved April 25, 2017, from https:// books.google.co.in/books?hl=en\&lr=lang_en\&id=GMB 5AgAAQBAJ\&oi=fnd \&pg $=$ PA $155 \& \mathrm{dq}=\mathrm{Cow}-$ an, + N. $+(2005) .+$ Working + memory + capacity\&ots $=q-$ sUgosU3gF\&sig=uwG_shnBHxoMTnTZ6V8XcLttnew $\# \mathrm{v}=$ onepage \&q\&f$=$ false.

Cowan, N. (2008). What are the differences between longterm, short-term, and working memory? Progress in brain research, 169, 323-338. doi:10.1016/S00796123(07)00020-9.

Denhovska, N., Serratrice, L., \& Payne, J. (2016). Acquisition of second language grammar under incidental learning conditions: The role of frequency and working memory. Language Learning, 66(1), 159-190. doi:10.1111/ lang.12142. 
Engle, R. W., \& Kane, M. J. (2003). Executive attention, working memory capacity, and a two-factor theory of cognitive control. Psychology of learning and motivation, 44, 145-199. doi:10.1016/S0079-7421(03)44005-X.

Engle, R. W., Tuholski, S. W., Laughlin, J. E., \& Conway, A. R. (1999). Working memory, short-term memory, and general fluid intelligence: a latent-variable approach. Journal of experimental psychology: General, 128(3), 309-331. Retrieved August 30, 2017, from http://englelab.gatech.edu/1999/working-memory2c-short3dterm-memory2c-and-general-fluid-intelligence.pdf

Erçetin, G., \& Alptekin, C. (2013). The explicit/implicit knowledge distinction and working memory: Implications for second-language reading comprehension. Applied Psycholinguistics, 34(4), 727-753. doi:10.1017/ S0142716411000932.

Fenesi, B., Sana, F., Kim, J. A., \& Shore, D. I. (2015). Reconceptualizing working memory in educational research. Educational Psychology Review, 27(2), 333351. doi:10.1007/s10648-014-9286-y.

Goo, J. (2012). Corrective feedback and working memory capacity in interaction-driven L2 learning. Studies in Second Language Acquisition, 34(3), 445-474. doi:10.1017/S0272263112000149.

Grey, S., Williams, J. N., \& Rebuschat, P. (2015). Individual differences in incidental language learning: Phonological working memory, learning styles, and personality. Learning and Individual Differences, 38, 44-53. doi:10.1016/j.lindif.2015.01.019.

Harrington, M., \& Sawyer, M. (1992). L2 working memory capacity and L2 reading skill. Studies in Second Language Acquisition, 14(1), 25-38. doi:10.1017/ S0272263100010457.

Hummel, K. M., \& French, L. M. (2016). Phonological memory and aptitude components: Contributions to second language proficienc . Learning and Individual Differences, 51, 249-255. doi:10.1016/j.lindif.2016.08.016.

Indrarathne, H. D., \& Kormos, J. (2017). The role of working memory in processing L2 input: insights from eye-tracking. Bilingualism: Language and Cognition, In Press. Retrieved April 24, 2017, from http://eprints. lancs.ac.uk/84627/1/Bilingualismarticle.pdf.

Izumi, S., \& Bigelow, M. (2000). Does output promote noticing and second language acquisition? Tesol Quarterly, 34(2), 239-278. doi:10.2307/3587952.

Jackson, D. O. (2016). Working memory and second language acquisition: Theory and findings. The Journal of Kanda University of International Studies, 28, 21-47. Retrieved April 25, 2017, from http://s3.amazonaws. com/academia.edu.documents/44157432/Jackson_16. pdf?AWSAccessKeyId=AKIAIWOWYYGZ2Y53UL3 A \& Expires $=1493086681 \&$ Signature $=\mathrm{FCe} 0 \%$ 2 F Um 5 zqpZk1\%2 F Nmk59t4 c 815k\%3 D\&response-content-disposition $=$ inline $\% 3 \mathrm{~B} \% 20$ filename\%3DWorking_memory_and_second_langua.

Juffs, A. (2004). Representation, processing and working memory in a second language. Transactions of the Philological Society, 102(2), 199-225. doi:10.1111/j.00791636.2004.00135.x.
Juffs, A., \& Harrington, M. (2011). Aspects of working memory in L2 learning. Language Teaching, 44(2), 137166. doi:10.1017/S0261444810000509.

Kormos, J., \& Sáfár, A. (2008). Phonological short-term memory, working memory and foreign language performance in intensive language learning. Bilingualism: Language and cognition, 11(2), 261-271. doi:10.1017/ S1366728908003416.

Leeser, M. J. (2007). Learner-based factors in L2 reading comprehension and processing grammatical form: Topic familiarity and working memory. Language Learning, 57(2), 229-270. doi:10.1111/j.1467-9922.2007.00408.x.

Linck, J. A., Osthus, P., Koeth, J. T., \& Bunting, M. F. (2014). Working memory and second language comprehension and production: A meta-analysis. Psychonomic Bulletin \& Review, 21(4), 861-883. doi:10.3758/s13423-0130565-2.

Mackey, A., \& Sachs, R. (2012). Older learners in SLA research: A first look at working memory, feedback, and L2 development. Language Learning, 62(3), 704-740. doi:10.1111/j.1467-9922.2011.00649.x.

Mackey, A., Adams, R., Stafford, C., \& Winke, P. (2010). Exploring the relationship between modified output and working memory capacity. Language Learning, 60(3), 501-533. doi:10.1111/j.1467-9922.2010.00565.x.

Martin, K. I., \& Ellis, N. C. (2012). The roles of phonological short-term memory and working memory in L2 grammar and vocabulary learning. Studies in Second Language Acquisition, 34(3), 379-413. doi:10.1017/ S0272263112000125.

MedicineNet. (2017, January 25). Medical Definition of Working memory: Working memory: Short-term (recent) memory. Retrieved April 24, 2017, from Medicine.net: http://www.medicinenet.com/script/main/art.asp?articlekey $=7143$.

Pavlenko, A. (1999). New approaches to concepts in bilingual memory. Bilingualism: Language and Cognition, 2(3), 209-230. Retrieved April 22, 2017, from https:// www.cambridge.org/core/journals/bilingualism-language-and-cognition/article/new-approaches-to-concepts-in-bilingual-memory/585564C043CFECA8E2BF325C0B7DA46A.

Révész, A. (2012). Working memory and the observed effectiveness of recasts on different L2 outcome measures. Language Learning, 62(1), 93-132. doi:10.1111/j.14679922.2011.00690.x.

Robinson, P. (1995). Attention, memory, and the "noticing" hypothesis. Language learning. 283331, 45(2), 285-331. Retrieved April 22, 2017, from http://s3.amazonaws.com/academia.edu. documents/39764988/1995_Robinson_noticing_hypothesis_1995_copy.pdf?AWSAccessKey Id=A K I A I W OW Y Y GZ 2 Y 53 UL 3 A \& Ex pires $=1492830714 \&$ Signature $=Z 7 H E K c J \% 2 B v t-$ wHnktKBh0tdH\%2FdaGQ\%3D\&response-content-disposition=inline $\% 3 \mathrm{~B} \% 20$ filename $\%$

Robinson, P. (2005). Aptitude and second language acquisition. Annual Review of Applied Linguistics, 25, 46-73. doi:10.1017/S0267190505000036. 
Sagarra, N. (2017). Longitudinal effects of working memory on L2 grammar and reading abilities. Second Language Research, 0267658317690577. doi:10.1177/0267658317690577.

Sagarra, N., \& Herschensohn, J. (2010). The role of proficiency and working memory in gender and number agreement processing in L1 and L2 Spanish. Lingua, 120(8), 2022-2039. doi:10.1016/j.lingua.2010.02.004.

Schmidt, R. W. (1990). The role of consciousness in second language learning1. Applied linguistics, 11(2), 129-158. Retrieved April 22, 2017, from http://s3.amazonaws.com/academia.edu. documents/45163874/4-SCHMIDT-The-roleof-consciousness-in-SLA.pdf?AWSAccessKey Id=AKIA I W O W Y Y GZ2 Y 53 UL 3 A \& Ex pires $=1492832054 \&$ Signature $=o$ RyFRQ7vIo4SF dUoRHAQ9b61rsQ\%3D\&response-content-disposition $=$ inline $\% 3 \mathrm{~B} \%$ 20filename $\% 3 \mathrm{DThe}$

Schrauf, R. W., \& Rubin, D. C. (1998). Bilingual autobiographical memory in older adult immigrants: A test of cognitive explanations of the reminiscence bump and the linguistic encoding of memories. Journal of Memory and Language, 39(3), 437-457. doi:10.1006/ jmla.1998.2585.

Skehan, P. W., \& Willis, D. (1996). Second language acquisition research and task-based instruction. Readings in Methodology, 13-23. Retrieved April 22, 2017, from http://s3.amazonaws.com/academia.edu.documents/33668601/Readings_in_Methodology_-Current Trends_in_Teaching_Second_Language_Vocabulary. pdf?AWSĀccessKeyId=AKIAIWOWYYG GZ2Y53UL3 A\&Expires $=1492848817 \&$ Signature $=V x K A-$ KVgNxBbTOfnQCXD3Ze7On3Q\%3D\&response-content-dis.
Swanson, H. L., Orosco, M. J., Lussier, C. M., Gerber, M. M., \& Guzman-Orth, D. A. (2011). The influence of working memory and phonological processing on English language learner children's bilingual reading and language acquisition. Journal of Educational Psychology, 103(4), 838. doi:10.1037/a0024578.

Tellier, M. (2008). The effect of gestures on second language memorisation by young children. Gesture, 8(2), 219235. doi:10.1075/gest.8.2.06tel.

Ullman, M. T., \& Lovelett, J. T. (2016). Implications of the declarative/procedural model for improving second language learning: The role of memory enhancement techniques. Second Language Research(Special Issue), 1-27. doi:10.1177/0267658316675195.

Van den Noort, M. W., Bosch, P., \& Hugdahl, K. (2006). Foreign language proficiency and working memory capacity. European Psychologist, 11(4), 289-296. doi:10.1027/1016-9040.11.4.289.

Verhagen, J., \& Leseman, P. (2016). How do verbal shortterm memory and working memory relate to the acquisition of vocabulary and grammar? A comparison between first and second language learners. Journal of experimental child psychology, 141(January), 65-82. doi:10.1016/j.jecp.2015.06.015.

Vulchanova, M., Foyn, C. H., Nilsen, R. A., \& Sigmundsson, H. (2014). Links between phonological memory, first language competence and second language competence in 10-year-old children. Learning and Individual Differences, 35(October), 87-95. doi:10.1016/j.lindif.2014.07.016.

Wen, Z. (2012). Working memory and second language learning. International Journal of Applied Linguistics, 22(1), 1-22. doi:10.1111/j.1473-4192.2011.00290.x

Wen, Z. (2014). Theorizing and measuring working memory in first and second language research. Language Teaching, 47(2), 174-190. doi:10.1017/S0261444813000517. 